\title{
PROCESSOS SOCIAIS DE EXCLUSÃO E POLÍTICAS PÚBLICAS DE ENFRENTAMENTO DA POBREZA
}

\author{
José Rogério Lopes
}

\begin{abstract}
O texto revisa contribuições teóricas de autores que abordam os processos de "exclusão social" como um conjunto de referências configuradas historicamente na dinâmica de internacionalização da economia. Dessa revisão, indica a necessidade de se distinguir entre as políticas públicas de "combate à exclusão" e aquelas que se auto-atribuem um caráter de inclusão, para justificar a complementaridade de ambas. Destacam-se categorias e elementos de análise (como o debate atual entre redistribuição e reconhecimento, no campo das reivindicações de direitos e das políticas públicas) que permitem identificar novos condicionamentos sociais que afetam os sentidos produzidos pelos sujeitos em condições de vulnerabilidade ou privações geradas na pobreza urbana, importantes para orientar uma revisão das diretrizes das políticas em questão.
\end{abstract}

PALAVRAS-CHAVE: processos de exclusão, internacionalização da economia, políticas públicas, vulnerabilidades, privações.

\section{INTRODUÇÃO}

Hoje, na medida em que a sociedade contemporânea se afasta dos ideais e referências do Estado de Bem-Estar Social - contexto no qual o controle social era exercido na perspectiva da configuração de um Estado totalizante ${ }^{1}$ (Marcuse, 1967) - emerge um conjunto de novos condicionamentos sociais que tendem a subsumir as formas de controle social em novas formas de sociabilidade (Zaluar, 1997).

Entre as formas emergentes de sociabilidade, aquelas que se enformam no quadro das ações e relações que se costumou denominar de exclu-

* Professor Titular do Programa de Pós-Graduação em Ciências Sociais na Universidade do Vale do Rio dos Sinos - Unisinos/RS

Av Unisinos, 950 Cristo Rei. Cep: 93022-000 - São Leopoldo - Rio Grande do Sul - Brasil. jrlopes@unisinos.br

${ }^{1}$ Sobre a perspectiva do Estado totalizante, Marcuse (1967, p. 25) afirma que se trata de "uma coordenação técnicoeconômica não terrorista que opera através da manipulação das necessidades por interesses adquiridos", e "se afirma através dos seus poderes sobre o processo mecânico e sobre a organização técnica do aparato" produtivo. Ao mesmo tempo, esse Estado busca produzir uma gama muita extensa de informações sobre as necessidades dos indivíduos, capacitando-se a melhor controlá-los. são social são importantes para análise, ou por sua multidimensionalidade ou pela complexidade causal.

De fato, a concepção de exclusão social costuma ser relacionada a um plano de causalidade complexo e multidimensional, diferenciando-se da concepção de pobreza, sobretudo porque aquela é uma condição produzida na emergência do neoliberalismo, caracterizada pela estratégia de sobredeterminação constante dos termos que fundam e reproduzem os jogos contemporâneos entre mercado, trabalho, Estado, poder e desejos. Enquanto a pobreza é um desdobramento das relações históricas e estruturais de oposição entre os interesses de classes, portanto, um fenômeno econômico que se configura na questão social derivada das relações capital versus trabalho, a exclusão social se caracteriza por um conjunto de processos que se estabelecem no campo alargado das relações sociais contemporâneas: a precarização do trabalho (Antunes, 1994), a desqualificação social (Paugam, 1999), a desfiliação social (Castel, 1999), a desagrega- 
ção identitária (Bauman, 2005), a desumanização do outro (Honneth, 1992) e a anulação da alteridade (Xiberras, 1993; Sung, 2002).

Tais processos geralmente são responsabilizados pela emergência ou difusão de outros fenômenos: o desemprego estrutural, a população de rua, a fome, a violência, a falta de acesso a bens e serviços, à segurança, à justiça e à cidadania, entre outros.

As condições que configuram a pobreza confirmam a dimensão de sujeito do pobre, na razão do controle de sua participação na economia, uma vez que a gênese do capitalismo pôs em evidência a produção da pobreza em massa, de forma mais homogênea que a aquela produzida no desenvolvimento do sistema, entre o final do século XIX e meados do século XX.

O desenvolvimento das relações produtivas envolveu essa massa de pobres numa estrutura dinâmica de condições e fatores diversos, impondo aos sujeitos a criação e a efetivação de estratégias de sobrevivência que começaram a se diferenciar, na medida em que:

- esses fatores afetam os indivíduos de formas diferentes, de acordo com sua inserção na sociedade; seu efeito dependerá da posição de cada indivíduo em termos de relações de produção (Dupas, 1999, p.28); ${ }^{2}$

- sua consciência de classe (ou sentimento de pertencimento) definiu orientações distintas de agregação ou articulação em torno de organizações de defesa de seus interesses ou de reivindicação pela satisfação de suas necessidades.

Nesse sentido, a própria experiência decorrente dos movimentos de reivindicação das classes trabalhadoras, que se especializaram em âmbito local, regional e nacional, ao invés de se inter-

2 Essa idéia se aproxima da concepção de "situação de classe", em Weber (1982, p.212), expressa "mais sucintamente como a oportunidade típica de uma oferta de bens, de condições de vida exteriores e experiências pessoais de vida, e na medida em que essa oportunidade é determinada pelo volume e tipo de poder, ou falta deles, de dispor de bens ou habilidades em benefício de renda de uma determinada ordem econômica. A palavra 'classe' refere-se a qualquer grupo de pessoas que se encontrem na mesma situação de classe". O destino dos sujeitos de uma dada classe social seria "determinado pela oportunidade de usar, em proveito próprio, bens e serviços no mercado" (p.214). nacionalizarem, permite afirmar que, hoje, "grupos que partilham a mesma pobreza chegaram lá de diferentes maneiras e têm diferentes probabilidades de saírem dela” (1999, p. 29).

Essa idéia pressupõe, também, que a pobreza produz lugares, como contextos nos quais ocorrem formas distintas de organização dos sujeitos, como atores sociais que participam dos diferentes modos de produção. Na visão de Santos (1997), os sujeitos caracterizam-se como atores sociais à medida que são reconhecidos como elementos presentes na configuração das estruturas ${ }^{3}$ que interagem para a constituição da realidade social. Evidentemente, essa presença interagia, e ainda interage como força, na constituição dos mecanismos de controle social.

A própria lógica de constituição dos direitos que enformam o ideal de cidadania, nas sociedades ocidentais, seguiu esses condicionamentos (Lopes, 2001a), de forma que sua universalização tornou-se mais um problema que uma solução. Ou seja, como tais direitos foram se institucionalizando, ao passo que as reivindicações das classes trabalhadoras foram se diversificando e se localizando, no desenvolvimento do jogo de forças entre elas e o capital, estabeleceu-se uma gradação no acesso a tais direitos que resultou em uma hierarquia dos sujeitos assistidos por eles assistidos. Essa hierarquia estaria na base mesma da distinção que Rosanvallon (1995) elabora entre droits-libertés e droits-créances (direitos-libertados e direitos-créditos), que pressupõem a liberdade política e a condição da redistribuição das riquezas. E aqui surge uma hipótese de trabalho um tanto polêmica: a de que a hierarquia dos assistidos pelos direitos de cidadania corresponde a uma estratificação das

${ }^{3}$ Santos apropria-se da idéia formulada por F. Perroux, segundo a qual uma estrutura "se define por uma "rede de relações, uma série de proporções entre fluxos e estoques de unidades elementares e de combinações objetivamente significativas dessas unidades"” (Santos, 1997, p.16), para argumentar que "as estruturas [...] são formadas de elementos homólogos e de elementos não homólogos. Entre as primeiras estão as estruturas demográficas, econômicas, financeiras, isto é, estruturas da mesma classe e que, de um ponto de vista analítico, podem-se considerar como estruturas simples. As estruturas não homólogas, isto é, formadas de diferentes classes, interagem para formar estruturas complexas. [...] A realidade social, tanto quanto o espaço, resultam da interação entre todas essas estruturas" (p.16-17). 
condições de inserção dos trabalhadores no mercado, que hoje se explicita em uma disputa pela permanência no próprio mercado, como uma das novas formas de controle social.

Se, antes, a condição de inserção no mercado condicionava a configuração dos lugares próprios dos sujeitos, hoje o próprio mercado tornou-se o lugar dos sujeitos.

A importância dessa formulação está assentada na necessidade de se perceber que o ideal de igualdade, que se produz e reproduz no quadro do desenvolvimento de tais relações, nas sociedades ocidentais, desdobra-se da determinação reconhecida na e pela igualdade do trabalho. Ora, se tal hipótese se confirmar, há duas questões daí derivadas que merecem nossa atenção: uma refere-se ao potencial de autonomia do sujeito contemporâneo, sobretudo daquele que trabalha, ou procura trabalho; outra se refere ao reconhecimento dos tipos e graus de solidariedade que os sujeitos são capazes de estabelecer, nas suas relações em sociedade.

\section{SOCIEDADE,POBREZAEPOLÍTICAS PÚBLICAS}

Esse contexto, sucintamente configurado, permite que se estabeleça um paralelo entre a gênese e o desenvolvimento da pobreza - discutidos anteriormente - e aquilo que denominávamos de sociedade.

Como formulação abstrata, segundo Dubet (1996), a sociedade pode ser apreendida nas elaborações sociológicas clássicas por cinco critérios: moderna, sistêmica, Estado-Nação, industrial; e o ator social. vertente subjetiva do sistema.

A medida desses critérios explicita uma orientação fundamental para essa análise. Dubet (1996, p. 41-50) assim os justifica:

- a sociedade é moderna e a sociologia é evolucionista, pois estuda e explica "a história da humanidade como um processo que vai da tradição do primitivo das tribos para o moderno, para a divisão do trabalho" (a tradição da modernidade);

- a sociedade é sistêmica, não porque toda ela seja sistêmica, ${ }^{4}$ e sim porque explicar a vida social tem implicado em para quê as coisas servem no interior do sistema, segundo as relações funcionais que os diversos elementos mantêm, nas sociedades complexas;

- a sociedade é um Estado nacional, porque se encarna em uma forma particular, que é o Estado-nação, em uma integração funcional sistêmica de uma economia nacional, de uma cultura nacional e de um sistema político nacional, quer seja ela pensada como efetivada pela burguesia, pelo Estado ou pela cultura;

- a sociedade é industrial, o que pressupõe reconhecer e explicar os conflitos de classes dominantes; esse reconhecimento assume, pelo menos, duas formas teóricas gerais: a primeira é a de que a integração social não pode ocorrer sob a lógica de tais conflitos, pois eles opõem antagonicamente as classes sociais; a segunda é a de que o conflito de classes reforça a integração social, porque se trata de um conflito negociável sob o manto da democracia; ${ }^{5}$

- na sociedade, o ator é o sistema, ou seja, o ator social é definido como a vertente subjetiva do sistema; meus sentimentos amorosos, minhas opiniões políticas, minha maneira de vestir, são o produto da minha socialização, isto é, a maneira como eu me integrei subjetivamente nos objetivos do sistema.

E aqui, Weber (1982) deve ser lembrado, quando afirma que o sistema é produzido pelos atores. Dessa complementaridade, pode-se afirmar que a ordem social se explica pela ação social socializada (Dubet, 1996, p. 23).

Pode ser incluída nessa formulação das so-

${ }^{4}$ Lembrem-se da distinção que Habermas (1990) elabora entre mundo vivido e mundo sistêmico. No primeiro, marcado pela reprodução simbólica (interação), o autor refere-se à experiência comum a todos os indivíduos "atores", na qual se reflete o óbvio e o questionamento do feito das certezas, que são possíveis a partir da ação comunicativa. Já no segundo, realiza-se a razão instrumental, objetivada nos subsistemas econômico e político, que desenvolvem mecanismos auto-reguladores - o dinheiro (capital) e o poder (burocracia) -, os quais permitem a "integração sistêmica". Essa distinção é também discutida em Freitag (1990).

${ }^{5}$ Perceba-se que, para cada uma dessas formas gerais, podem-se constatar também modos distintos de efetivação do controle social. 
ciologias clássicas uma sexta categoria, relacionada à dinâmica de formação e desenvolvimento social, estruturada no fato de que a sociedade é institucionalizada (uma contribuição antropológica sobre o processo de socialização). Ou seja, a institucionalização implica reconhecer que não só o ator é o sistema, mas que a modernidade, a industrialização e a formação do Estado-nação se reproduzem através da formação de vínculos institucionalizados em divisões sociais: classes, segmentos, categorias de sujeitos, grupos, entre outras.

A importância desse último critério está fundamentada na concepção de que a instituição tem historicidade e autoridade moral (Berger; Berger, 1977) e que é ela que promove a reflexividade da vida moderna, segundo Giddens (1991). Isso implica reconhecer que os critérios de injustiça eram delineados institucionalmente.

Porém a maneira como esses critérios imbricaram-se, na produção da sociedade, implicou um movimento constante e dinâmico da figura do sujeito, da categoria de pobreza, das condições de trabalho e dos modelos de integração social (além, é lógico, das próprias idéias de Estado e de mercado) (Dubet, 1996; Zaluar, 1997).

Nesse sentido, uma análise comparativa elaborada entre Estados Unidos, França e Brasil (Kowarick, 2003) identificou uma variação de combinações assimétricas desses elementos, conforme foram se organizando em políticas sociais, nessas sociedades concretamente estabelecidas, segundo os critérios anteriormente definidos. Essa diversidade indica equívoco daquele que pretende explicar as condições atuais pela presença e o papel dos atores sociais fundantes dessa relação: a burguesia, os trabalhadores e o Estado (sendo que a pobreza desdobrar-se-ia como uma das condições da segunda categoria de atores).

Segundo Zaluar (1997, p. 4),

Na sociedade atual, em que as classes sociais, tais como foram reconhecidas e analisadas no século XIX e na primeira metade deste, não são mais as únicas divisões relevantes, segmentarizações múltiplas criaram outras exclusões e novos sujeitos de direito nas lutas que se seguiram.
Mais que isso, o desenvolvimento das sociedades mostra que algumas dessas figuras tornaram-se difusas, chegando quase ao anonimato, nesse processo. ${ }^{6}$ Isso decorreu, sobretudo, de dois fatores interligados: a sociedade manteve-se sistêmica e, mais que isso, ampliou a cobertura do mundo sistêmico sobre o mundo vivido; por outro lado, a economia, antes um componente funcional da integração promovida pelo Estado nacional, tornou-se o próprio modelo de integração, na medida em que se internacionalizou.

A internacionalização da economia foi uma sobredeterminação do componente-meio para um componente-fim, rompendo com a configuração e a soberania do Estado-nação (Martins, 1996; Carvalho, 1997). Rompe-se também com a idéia de sociedade e, em extensão, com a idéia de sujeito (como ator social), na medida em que a internacionalização da economia transformou a razão ou a racionalidade que sustentava os vínculos entre os atores sociais (Touraine, 2006).

É na raiz dessa transformação que emerge a concepção de exclusão social, “... que vem a ser, portanto, um traço constitutivo da classificação na qual se baseia o conceito estrutural de identidade social.” (Zaluar, 1997, p. 2). E aqui importa perceber que esse traço afeta a concepção de desigualdade, como afirma Carvalho (1997, p. 16): "A pobreza assume na contemporaneidade um significado excludente. É nessa condição que a desigualdade social é também ressignificada, sinalizando novos processos de discriminação e apartação social.”.

Ou ainda, segundo H. Arendt (apud Maiolino; Mancebo, 2005, p. 17):

A exclusão social apareceria como a face rejeitada do neoliberalismo globalizado, para cujos integrantes não há nenhuma política assistencialista [...] (e) no lugar da idéia de um exército industrial de reserva [...] teríamos a idéia do estorvo, da exclusão, a imputação de uma sub-humanidade aos grupos, cada vez mais numerosos.

\footnotetext{
${ }^{6} \mathrm{Ou}$ seja, as classes trabalhadoras foram substituídas pelos sindicatos e outras organizações classistas, a burguesia e sua expressão capitalizada, na forma do empresariado, foram substituídas pelo mercado, e o Estado foi substituído pela competição partidária na disputa pelos governos.
} 
Nesse contexto, constatam-se as dificuldades atuais das políticas sociais e da diversidade de programas públicos de combate à pobreza ou à exclusão, que ignoram o traço constitutivo de tal classificação e se debatem entre posições defensivas de modelos de integração nacional ou em pequenos grupos e comunidades (Zaluar, 1997), sem apreender ou atender às mudanças significativas no caráter das injustiças sociais. Ou seja, elas continuam a reproduzir critérios de injustiça delineados institucionalmente. Tais políticas se propõem universais, mas passaram a ser focalizadas em seu direcionamento de privilegiarem ora os processos de exclusão (o chamado “combate à exclusão”), ora os de inclusão (as chamadas políticas inclusivas) (Souza, 2004; Ivo, 2004).

Essa focalização foi acompanhada, na última década, de um processo de descentralização que pressupõe um melhor reconhecimento das demandas dos sujeitos excluídos, mas que produz uma "reconversão do social" (Ivo, 2004) e impõe aos governos locais a sua gestão, conforme indica Celina Souza (2004). Complementar a esse processo, "a tendência à interconexão mais direta entre o global e o local deslocam o Estado-Nação para uma zona de mediação, mais do que de decisão autônoma" (Carvalho, 1997, p.18), o que colabora para a reprodução de tal indecisão.

Urge, assim, rever os pressupostos teóricos dos processos sociais de exclusão e buscar apreender os registros empíricos que se configuram em tais processos, sobretudo os que se produzem nas “... zonas sombreadas [...] dos processos de integração” (Zaluar, 1997, p. 2), para enfatizar a necessidade de efetivar políticas públicas que cubram os critérios concretamente demandados nos planos e setores da vida social por eles afetados.

\section{EXCLUSÃO SOCIAL: registros teóricose políticos, exógenos e endógenos}

A concepção de exclusão social aparece de maneira diversificada. Pode-se pensar seu aparecimento segundo modelos distintos de análise, con- forme o lócus ou o foco das diferentes abordagens. Enquanto alguns autores optaram por debater o estatuto teórico do conceito (Nascimento, 1994; Oliveira, 1997), denunciando a ilusão projetada na oposição entre excluídos e incluídos (entendendo que exclusão e inclusão são processos complementares produzidos dialeticamente na dinâmica econômica da sociedade capitalista), outros investigaram os "processos sociais excludentes" (Martins, 1997; Zarth, 1998; Veras, 1999; Cattani, 2005) e mostraram que a complementaridade entre exclusão e inclusão é cada vez menos regular, no capitalismo contemporâneo, em prejuízo do segundo processo.

Essas tendências são importantes, pois abordam processos nos quais os sujeitos pobres projetam idealizações e identificações com mudanças de suas condições. Na primeira tendência, prevalece a abordagem dos processos de controle da participação dos pobres na economia, embora se visualize uma abertura aos processos políticos; na segunda, se reconhece uma porosidade já estabelecida entre processos econômicos e políticos e uma abertura para a potencialidade de mudanças também nos processos culturais.

Essa reflexão está alinhada à segunda tendência, na qual se destacam os trabalhos de Atkinson (1998) e de Rogers, Gore e Figueiredo (1995), essenciais para a compreensão da emergência da concepção de exclusão social. O primeiro explicita o caráter dinâmico e a natureza multidimensional da exclusão social, além da extensão desse processo a campos sociais mais amplos que a participação na vida do trabalho.

O segundo, uma coletânea organizada pelos autores, circunscreve a gênese da exclusão social em fenômenos concretos ocorridos na Europa, desde finais da década de 1970, como o aumento da pobreza urbana, a falta de perspectiva e a insegurança causadas pelo desemprego entre jovens e adultos, a falta de acesso a emprego ou renda nas minorias étnicas e entre imigrantes. São fenômenos relacionados à internacionalização da economia e à revolução tecnológica, e os textos dessa coletânea, além de confirmarem a natureza 
multidimensional dos processos de exclusão, analisam parte da literatura existente e enumeram categorias de excluídos nas diversas sociedades. ${ }^{7}$

Um ponto de convergência entre essas obras é o do contexto nacional, importante nas reflexões sobre os processos de exclusão, que coincidem em torno da bibliografia francesa sobre o assunto. Essa localização está assentada no descompasso enfatizado entre os processos de modernização e os processos de "globalização" que afetam as sociedades nacionais, com seus desdobramentos analíticos das transformações na formação e no desenvolvimento do Estado-Nação.

$\mathrm{Na}$ abordagem empregada neste artigo, a ênfase em uma bibliografia francesa tem a ver com tal descompasso, pensado como preocupação da teoria social. Daí que, em princípio, pode-se pensar a questão da exclusão a partir da nacionalidade de algumas reflexões sobre a modernidade. No caso francês, predomina a perspectiva da autonomia definida no campo das ações de cidadania; no caso inglês, a perspectiva do mercado como agente do desenvolvimento; no caso americano, a instituição como ator social.

Quais são as implicações dessa configuração?

A primeira diz respeito à herança que recebemos, na sociedade brasileira, que fundiu os modelos de reflexão sobre tais perspectivas, gerando uma tensão no campo teórico, marcado pela inserção periférica nesse debate (Souza, 2004a). Assim, aquilo que hoje justificamos como um campo plural de reflexões seria um pano de fundo para explicar nossas próprias indecisões sobre os rumos que devemos tomar. A segunda diz respeito a essa própria indecisão, na medida em que ela obnubila uma teleologia acerca da ação do sujeito na contemporaneidade, colocando-nos em um labirinto.

Por outro lado, a história da organização local das variáveis que movimentam as relações desiguais, no desenvolvimento do capitalismo, assim como os

${ }^{7}$ Esse último aspecto está considerado no texto de Hilary Silver, na mesma coletânea, intitulado Reconceptualizing social disadvantage: three paradigms of social exclusion, no qual o autor identifica 25 categorias de indivíduos caracterizados como excluídos, nos estudos das décadas de 1980 e 1990, na Europa. sistemas explicativos elaborados para compreender esses processos, dão conta de explicitar nossa condição "privilegiada” de análise dos mesmos.

Segundo Wanderley (2004), a organização local das variáveis desiguais caracteriza uma condição que deve ser pensada desde uma longa duração da questão social, configurada no contexto latino-americano e caribenho. E, embora a noção seja ambígua,

... ela se transforma efetivamente em questão social quando é percebida e assumida por um setor da sociedade, que tenta, por algum meio, equacioná-la, torná-la pública, transformá-la em demanda política, implicando em tensões e conflitos sociais (p. 59).

Nessa visão, a problematização da questão social na América Latina necessita uma inserção espaciotemporal diferente da realidade européia. Na visão de Wanderley, ela abrange elementos que historicizam a problemática geral, emergindo com o tema indígena, seguido pela formação nacional, pelas temáticas negra, rural, operária, e da mulher, como proposições histórico estruturais.

Porém, o autor enfatiza que a globalização compreendida como um processo desenvolvido pelo capitalismo desde suas origens - com mudanças que mundializam mercados, finanças, comunicações e valores culturais, criando um sistema de vasos comunicantes entre os países e continentes, faz com que a questão social adquira hoje novas formas e conteúdos. Uma vez que a globalização comporta a existência de fraturas e contradições que, na América Latina, se evidenciam mais profundamente, a mesma se manifesta como subordinada e assimétrica, como "matriz de novos conflitos" (p. 67), configurando-se num sistema de ordem e desordem que não modificou a situação de "países de estruturas sociais heterogêneas", como na definição de Celso Furtado.

Isso implica que, tanto no desenvolvimento como na manifestação contemporânea das tematizações históricas da questão social na América Latina, elas surgem ora como problematizações sociais, econômicas e políticas, ora como éticas e filosóficas, com repercussões jurídico-políticas 
distintas. Eessas problematizações representam um parâmetro para o entendimento dos modelos de políticas sociais dos Estados latino-americanos.

Vistas desde o processo histórico mapeado pelo autor, essas políticas sociais enformaram “... um mix que engloba os modos de (des)articulação e (des)integração, nacional e regional, entre nação, Estado, cidadania, capital, trabalho" (Wanderley, 2004, p. 115), que podem ser caracterizados com um ponderável grau de universalidade. ${ }^{8}$ Entretanto, mesmo que a legislação social tenha avançado e seja pioneira (como nos casos de Uruguai e Chile do início do século XX), a situação de proteção social efetiva é precária na maioria dos países.

Nessa perspectiva, as políticas sociais dos Estados foram comprometidas pela “...continuidade da questão social de longa duração, calcada na desigualdade e injustiça estruturais, que não foram superadas pelos processos de emancipação do século XIX e de modernização do século XX.” (p. 126), da mesma forma que as concepções de pobreza e a noção de exclusão social também o foram. Prevalece, então, o processo de concentração de riquezas e de poder nas minorias ricas e de aumento dos pobres, com suas seqüelas dramáticas.

A distância entre (des)articulados e (des)integrados de ontem e de hoje é que os primeiros eram úteis ao regime vigente, que necessitava de seu trabalho, enquanto os últimos, afetados pela flexibilização e precarização do trabalho, são considerados como não-úteis ao processo de produção, não necessários. Instala-se, aí, a apartação social.

Retomando diacronicamente a evolução do processo e suas implicações para as políticas sociais, o autor reporta-se a Donzelot, à insociabilidade e periculosidade atribuídas ao marginalizado e à iniciativa de provê-los de proteção social, com suas ideologias subjacentes: a ajuda e a proteção sociais. Tais atribuições estariam sendo atualizadas pelas políticas sociais contemporâneas, desde a redefinição

${ }^{8}$ Nesse sentido, o autor reconhece, na influência do positivismo social na América Latina, algumas marcas da legislação social brasileira: a focalização, a privatização e a descentralização. Marcas de um modelo que entra em conflito com concepções universalistas e explicita os dilemas daí surgidos. das situações de vulnerabilidade: “... um vagalhão secular que tem marcado a condição popular do sinal da incerteza e, mais freqüentemente da infelicidade" (Castel, 2004, p. 132) que afeta os ameaçados de exclusão. Daí que a exclusão social deve ser vista no percurso, no e como processo, já que ela "não é um estado social dado, mas o resultado do modelo de desenvolvimento seguido, de seqüelas de um processo secular e que adquire novos contornos com o processo da 'globalização' e dos programas neoliberais” (Wanderley, 2004, p. 137).

Produzida como “... questão social ampla, histórica e estrutural, insolúvel na sua totalidade nos marcos da formação econômico-social capitalista realmente existente” (p. 131), a exclusão caracteriza-se pelo modelo de inclusão desigual e subordinada desenvolvida naquela formação.

A elaboração de Wanderley permite que se entendam as lógicas fundantes dos processos de exclusão desde uma longa duração da questão social, que se metamorfoseia historicamente em correspondência com as problematizações socialmente transformadas em demandas políticas. Essa elaboração permite, assim, que os sistemas explicativos elaborados para compreender tais metamorfoses da questão social, no caso brasileiro, também sejam revistos, de forma a enfatizar sua contribuição para a análise dos processos contemporâneos.

Nesse sentido, é possível verificar que as conseqüências do modelo de desenvolvimento capitalista, em nossa sociedade, produziram categorias de pensamento configuradas diacronicamente pelos fenômenos de marginalização (de influências notadamente modernizadoras e econômicas), de espoliação (de influências marcadamente territoriais) e de segregação (de influências geradas em uma tríplice dimensão: de classes, de raça-etnia e de relações de gênero) (Wanderley, 1997; Veras, 1999), que se inscreve de forma difusa nos territórios.

Tais categorias de pensamento orientaramse em uma crescente convergência de análises dos problemas urbanos, como já analisaram Maiolino e Mancebo (2005). Ocorre que essa convergência envolveu o debate de perspectivas distintas, des- 
de as décadas de 1960 e 70 . O debate sobre a marginalidade, por exemplo, orientado no marco de um estruturalismo histórico, afirmava que “... a existência marginal de um determinado elemento ou conjunto de elementos pode ser o resultado da natureza mesma da estrutura vigente da sociedade” (Quijano, 1978, p. 31), em contraposição à dualização social característica do estruturalismo funcionalista então vigente, que compreendia a existência marginal desses elementos no quadro de uma concepção de sistema social. ${ }^{9}$

Porém, refletindo sobre o processo de integração das populações marginais às dinâmicas estruturais do capitalismo, alguns autores pensavam a origem e o desenvolvimento do conceito de marginalidade a partir da falta de integração dos núcleos de moradores pobres (em geral, favelados e migrantes) "em relação aos serviços comunais que caracterizam a ecologia urbana das cidades" (Quijano, 1978, p.20), depois da segunda guerra mundial, de onde emergiram conceitos como massa marginal (Nun, 1969) e populações marginais, ou marginalizadas (Quijano, 1978). Na medida em que essa referência se generalizou demasiadamente nos estudos latino-americanos e brasileiros, autores como Kowarick (1975) e Berlinck (1975) criticaram a abrangência e imprecisão que ela foi assumindo, caracterizando-a estritamente em termos de inclusão ou exclusão dos trabalhadores no sistema produtivo, ao mesmo tempo em que apresentavam a concepção de espoliação urbana para especificar as interpretações e análises das variações marginais de integração das camadas pobres da

${ }^{9}$ Segundo Maiolino e Mancebo (2005, p. 15): "Sob essa perspectiva, toda existência marginal se configuraria numa forma, ao menos em parte, não integrada à sociedade, carecendo de certos ajustes setoriais que facilitassem a adaptação-integração. Tratava-se de desorganizações transitórias que, em analogia aos processos metabólicos dos organismos biológicos, poderiam ser assimiladas, sem a necessidade de maiores alterações sociais estruturais e sem modificações nas tendências fundamentais da própria sociedade [...]. Muitas análises desenvolvidas no Brasil, em torno da pobreza urbana, compartilharam dessa perspectiva teórica, atribuindo, p. ex. , ao massivo êxodo rural para o sudeste, a responsabilidade pelos problemas enfrentados nas grandes cidades, fossem eles de moradia mendicância, delinqüência, dentre outros. Esta vertente subsidiava, portanto, uma visão dualista da sociedade que oporia ao setor desenvolvido da sociedade um outro, marginal e não funcional, mas metabolizável, mediante a adoção de políticas específicas”. população nas grandes cidades.

$\mathrm{Na}$ década de 1980, esses sistemas explicativos se estendem das análises que se debruçam sobre segmentos marginalizados para a abordagem das implicações da marginalidade em termos de participação sociopolítica (marginalidade como cidadania limitada), no contexto da reorganização da sociedade civil (transição democrática, crescimento dos movimentos populares e sociais e redefinição do sistema partidário, entre outros aspectos).

Nesse movimento analítico, os segmentos marginalizados das cidades são compreendidos de um lugar ampliado, nos estudos acadêmicos, passando a ser analisados como elementos variáveis da organização do território (Santos, 1987), sobretudo, considerando-se as dificuldades desses grupos em participar do processo de desenvolvimento econômico e de ascensão social.

O sistema explicativo relevante nesse período aponta para estudos “...da democracia, da segregação urbana, a importância do território para a cidadania, a falência das ditas políticas sociais, os movimentos sociais, as lutas sociais" (Veras, 1999a, p. 31).

Já na década de 1990, com a difusão dos estudos europeus sobre os processos de exclusão, a concepção de marginalidade se atualiza novamente, passando a ser concebida ora em uma perspectiva multidimensional, como modos de marginalização (Martins, 1997), ora como um novo registro de apartação, definido como segregação (Ribeiro, 2000; Maricato, 2000), que retoma as análises de dualização social produzidas pelo aumento da desigualdade. Contudo, esses dois registros convergem e apontam para a produção de novas formas de discriminação, precarização ou vulnerabilidades sociais, no quadro das transformações contemporâneas, que especificam o potencial heurístico dos processos de exclusão. Da mesma forma, seja focalizando tais mudanças nos movimentos sociais, seja focalizando-as nas delimitações sócio-territoriais das desigualdades, essas perspectivas apontam também para uma necessária análise das profundas transformações que 
afetam a autonomia dos atores sociais. ${ }^{10}$

Dessa maneira, ao passo que avaliamos nossa inserção periférica no desenvolvimento da concretude dessas relações e no debate teórico acerca delas, redesenhamos a história da exclusão social no ocidente.

O desconhecimento desse processo pode acabar por confundir o real com o conceito, a concretude com a abstração. Ou seja, podemos confundir a escala de percepção dos problemas com a escala de sua resolução, como alertava Santos (1997).

A importância do debate brasileiro acerca dos processos de exclusão em voga, considerando a história e as mudanças existentes no desenvolvimento da questão social (Ianni, 2004; Pastorini, 2004; Wanderley, 2004) e das relações de desigualdade (Wanderley, 1997; Veras, 1999a; Souza, 2004a), permite afirmar que as condições que configuram a pobreza confirmam a dimensão de sujeito do pobre, na razão do controle de sua participação na economia. Porém, nos processos de exclusão produzidos no mundo neoliberal, mais que controlar ou negar o acesso ao trabalho ou ao consumo, controla e nega-se a própria condição de "sujeiticidade" (o que faz o ser humano ser sujeito ${ }^{11}$ ) do indivíduo (Sung, 2002, p. 19).

Essa transformação qualitativa dos pressupostos antes identificados com os problemas decorrentes da desigualdade socioeconômica (a exploração, a marginalização, a pobreza), permite entrever que a injustiça primordial não é mais exclusivamente socioeconômica ou material, mas também simbólica. Assim, Xiberras (1993, p. 18) afirma que os excluídos não são simplesmente rejeitados fisicamente, geograficamente ou materialmente. Eles não são simplesmente excluídos das riquezas materiais, isto é, do mercado de trocas. Os excluídos são-no também das riquezas espirituais: os seus valores têm falta de reconhecimento e es-

${ }^{10}$ A importância de tais contribuições já foi discutida em outro artigo deste autor (Lopes, 2007), onde se acentua a dimensão propositiva dos atores das lutas sociais latinoamericanas no enfrentamento dos processos de exclusão.

11 Jung Mo Sung utiliza o conceito de sujeiticidade em substituição ao de subjetividade, para aproximar a sua discussão ao pensamento de Hinkelanmert (1988). tão banidos do universo simbólico. E aqui não se trata de reavivar concepções como a de personalidade marginal, ou de incapacidades derivadas da inserção dos sujeitos em uma cultura da pobreza que, como já indicou Kowarick (2003), somente serviram para culpabilizar os pobres pela condição em que se encontram.

Os problemas decorrentes dessa injustiça simbólica caracterizam-se pela hostilidade, pela invisibilidade social e pelo desrespeito que a associação de interpretações ou estereótipos sociais reproduzem na vida cotidiana ou institucional. Esse tipo de comportamento implica prejuízo da autoestima de indivíduos e grupos, mediante processos intersubjetivos (Souza, 2000). Nesse quadro de produções atuais, trabalhos como os de Rosanvallon (1995) explicitam, em medidas diferentes, os prejuízos causados pelos processos de exclusão social nos condicionamentos que estruturam a vida coletiva e as políticas sociais contemporâneas, sobretudo por afetar o escopo de representações que se formou institucionalmente em torno da grande contradição moderna entre autonomia e liberdade, que define o estatuto do sujeito.

Rosanvallon (1995) busca superar a idéia de exclusão afirmada como incapacidade de satisfazer as necessidades, para mostrar que ela é um processo, com desdobramentos que afetam profundamente o psiquismo dos indivíduos, que precisarão, de agora em diante, se ressocializar. Ao analisar o escopo dos processos de exclusão em uma perspectiva política, afirma que é necessário requalificar o Estado para garantir o direito de os sujeitos excluídos viverem em sociedade.

A análise de Rosanvallon permite considerar o profundo impacto dos processos de exclusão nos indivíduos-sujeitos, ao discutir o caráter dos direitos sociais na contemporaneidade. ${ }^{12}$ Se-

${ }^{12}$ Ewald (1995), ao apresentar o estudo de Rosanvallon, afirma que o Estado-providência clássico é ineficaz no combate à exclusão e que ele funciona “... segundo uma lógica da amplificação das injustiças pelo engendramento de uma sociedade dual. [...] o Estado providência clássico [...] não pode mais pretender ser um princípio do contrato social, ligar a sociedade a ela mesma, na medida em que ele associa apenas uma fração da sociedade". Segundo o autor, "a percepção dos riscos sociais, como sua realidade, mudou”. Os indivíduos reconhecem que o principal risco não é mais o de perderem rendimentos 
gundo o autor, integrá-los pelo direito de inserção coloca em questão um tipo de norma fundamentada sobre o fato de que os indivíduos se encontram em situações singulares e que, então, devem ser tratados de maneira particular, para que se consiga uma verdadeira eqüidade.

Assim, está em jogo, atualmente, a relação entre fatores econômicos e fatores não-econômicos na produção da vida social (Touraine, 2000). Tal relação levou a uma revisão teórico-empírica da concepção de vulnerabilidade, que se projeta da esfera do sistema de proteções, configurado em torno do mundo do trabalho (Castel, 1999), para um campo ampliado de interações que, segundo Abramovay (2002, p. 30) traduz a situação em que o conjunto de características, recursos e habilidades inerentes a um dado grupo social se revela insuficiente, inadequado ou difícil para lidar com o sistema de oportunidades oferecido pela sociedade, de forma a ascender a melhores níveis de bem-estar ou diminuir probabilidades de deterioração das condições de vida de determinados atores sociais. Essa situação pode se manifestar, em um plano estrutural, por uma elevada propensão à mobilidade descendente desses atores e, no plano mais subjetivo, pelo desenvolvimento de sentimentos de incerteza e insegurança entre eles.

Nesse movimento, a razão da participação autônoma e (ou) solidária dos sujeitos, na produção da vida social, mudou substancialmente. Acima de tudo, ela foi condicionada por um gradual parcelamento dos ideais representativos, nas sociedades democráticas, ajustado ao reconhecimento das diferenças culturais, étnicas ou de gênero e às demandas da internacionalização da economia. No seio de tais mudanças, a hegemonia mundial adquiriu novos contornos, conforme foram se formando blocos continentais e intercontinentais de relações econômicas, entre países centrais e perifé-

em casos de infortúnio, mas o desemprego e a exclusão que segue dele; reconhecem o princípio de sua organização não mais na defesa da condição salarial, segundo uma lógica dos direitos e das liberdades, mas na procura de uma garantia do trabalho; reconhecem que o risco da exclusão não atinge somente "populações identificadas pelos status sócio-econômicos largos, como o assalariado, mas a indivíduos em função de histórias e de percursos sempre singulares". ricos do capitalismo, que reforçaram, em âmbito local, a fragmentação dos sistemas produtivos e a competitividade pelos postos de trabalho. A visibilidade desse fenômeno, no Brasil, mostra claramente que ele ultrapassou a esfera do trabalho formal (como emprego) para a do informal, reproduzindo, nessa esfera, os processos sociais excludentes.

\section{FINALIZANDO}

Essa reprodução foi constatada por pesquisas realizadas em regiões de desenvolvimento no sudeste e no sul do país, ${ }^{13}$ objetivando reconhecer as novas territorialidades urbanas produzidas na lógica do trabalho informal exercido nos espaços públicos, incluindo investigações sobre atividades variadas que vão dos coletores de materiais recicláveis aos vendedores de mercadorias contrabandeadas.

As transformações sociais contemporâneas, ocorridas no mundo da produção e do trabalho, ao produzirem uma crescente precarização da atividade remunerada e elevados índices de desemprego, expulsaram milhares de trabalhadores para o mercado informal na década de 1990, nessas regiões, gerando o conseqüente crescimento da economia informal. Isso tem provocado a proliferação de ocupações exercidas nos espaços antes reconhecidos como de circulação - ruas, praças e largos -, modificando a lógica do trabalho como atividade, que agora se confunde com o espaço ampliado da cidade. Nesse contexto, a distinção entre espaços de produção ou trabalho e espaços de circulação de pessoas e mercadorias é rompida, em prejuízo dos espaços públicos, gradualmente tomados por atividades ocupacionais e de geração de renda, modificando a percepção ambiental urbana e as identidades de vários segmentos sociais.

Assim, a ocupação de espaços públicos pelo trabalho informal, antes restrito às atividades de trocas tradicionais que ocorriam em espaços reduzi-

13 Sobre as pesquisas realizadas na região sudeste, ver Lopes (2001a). As pesquisas realizadas na região sul estão em progresso, concentradas em municípios da região metropolitana de Porto Alegre. 
dos e localizados, foi se difundindo por diversos espaços públicos que concentram circulação de pessoas, impondo intervenções dos governos locais.

Com a invasão desses locais pelos trabalhadores informais e os produtos de consumo modernos, os governos locais passam a ordenar os espaços de venda, com a delimitação de áreas como “camelódromos", ou "boxes", por setores de produtos, e a cobrar taxas de ocupação, fiscalizando eventualmente as atividades dos indivíduos.

Ocorre que tais ordenamentos, realizados geralmente de forma arbitrária, resultaram numa distribuição desigual dos espaços (considerando o potencial de venda de cada um, identificado pelos trabalhadores informais), hierarquizando os lugares e estratificando os trabalhadores informais segundo classes desiguais de inserção territorial.

Paralelamente ao estabelecimento desses mecanismos formais de ordenamento urbano do trabalho informal, identificaram-se também alguns mecanismos informais, operados por comerciantes e agentes fiscais dos governos locais, que agem sobre coletores de materiais recicláveis que atuam nas áreas comerciais dos municípios. Exemplo desses mecanismos é o estabelecimento de acordos tácitos entre comerciantes e coletores para a delimitação de horários fixos de entrega de papelões e outros materiais. Esse ordenamento informal limita o tempo de trânsito dos coletores e de suas carroças pelos calçadões dos centros comerciais das cidades aos períodos de abertura e fechamento do comércio, retirando-os da cena urbana durante os intervalos de maior movimentação dos compradores. ${ }^{14}$

Essas referências, entre outras coletadas, mostram que o aumento do desemprego, arrastando milhares de sujeitos para o mercado informal, produz uma forma de ocupação espontânea dos espaços públicos da cidade pelo trabalho, gerando a necessidade de novas políticas públicas e modelos para o ordenamento urbano (na forma de

${ }^{14}$ Esses acordos afetaram a dinâmica das relações de solidariedade que vinham se configurando entre os coletores, e destes com os comerciantes, gerando formas de competição encobertas por uma argumentação de pretensa urbanidade, no controle dos horários dos coletores. ações formais e informais) que agem sobre a distribuição espacial do trabalho informal. Trata-se de uma forma de controle que opera pela produção de reformas urbanas que parcelam os espaços públicos em zonas hierarquizadas de comércio informal nos municípios.

E esse ordenamento implica tensões e conflitos sociais, como afirmou Wanderley (2004, p. 59), uma vez que o controle do acesso dos trabalhadores informais ao espaço público é visto pelos próprios trabalhadores como desrespeito. Assim, as diversas manifestações desses trabalhadores, que vimos assistindo nas regiões pesquisadas, mas também outras presenciadas em capitais do país onde esse processo vem ocorrendo com regularidade, mostram que o parcelamento espacial imposto aos sujeitos em situação de vulnerabilidade não pressupõe a combinação entre o direito à diferença com a participação econômica. Essa combinação desdobra-se da necessidade de garantir que o acesso ao bem comum preserve a particularidade de cada um, o que implica, por outro lado, recuperar a capacidade de ação e de sentido dos atores sociais. E essa recuperação transita na contramão dos canais contemporâneos de controle soci$\mathrm{al},{ }^{15}$ evidenciando que as políticas públicas podem gerar um descompasso entre os planos das esferas prática e sensível da experiência social - a práxis, para Lefebvre (1977) - elemento forte e ainda pouco explorado nas análises sobre os processos de exclusão.

A experiência de viver tais processos de exclusão projeta-se nas representações dos sujeitos, de forma que as concepções de respeito e desrespeito são condicionadas pela maneira como elas os afetam. Para quem vive imerso em situações de vulnerabilidade ou precarização, a imagem da cidade emerge a uma "distância próxima" - proxi-

${ }^{15}$ Por exemplo, em passagem por Recife em 05/08/2008, este autor teve oportunidade de presenciar uma manifestacão dos ambulantes da cidade que, retirados do centro da cidade pelo governo local, armaram barricadas e queimaram pneus logo após a ponte que faz a ligação da orla para o centro da cidade, causando um congestionamento de cerca $40 \mathrm{~km}$, em vários sentidos. Em depoimentos que os líderes da manifestacão deram às TVs locais, destacava-se a reivindicação do retorno às áreas centrais da cidade, em uma distribuição negociada dos locais de inserção de seus pontos de venda. 
midade geográfica e distância social - e suas relações com o conjunto dos mecanismos institucionais da vida urbana têm sempre um fundo de desconfiança, descrédito ou desapego.

$\mathrm{Na}$ medida em que a produção da cidade contemporânea reforça os processos de exclusão sócio-territorial (Maricato, 2000), reproduzindo as estratégias de idealização da urbanidade e de vinculação do sujeito pobre à urbe - ou a uma parte dela - por meio da ocupação exercida por ele, essa ocupação permite um exercício de visualização da cidade que condiciona as representações, ações e reivindicações de direito à cidade e à cidadania.

As privações vividas por boa parcela da população das cidades contemporâneas, relacionadas à difusão desse modelo de idealidade e de vinculação dos sujeitos à urbe, extrapolam os processos de exclusão material e constituem violências simbólicas. Porém, mesmo submersos nas "zonas sombreadas [...] dos processos de integração" (Zaluar, 1997, p. 2), esses sujeitos procuram produzir outras estratégias de superação dos processos de exclusão no próprio cotidiano. Na representação difusa de cidade que esses sujeitos explicitam, evidencia-se a concepção de Ítalo Calvino (1990), de que uma cidade pode ser aquilo que dela se vê ou se entende. informal, o que leva os indivíduos a se sentirem desrespeitados. E aqui cabe lembrar a dimensão do papel da política social nas democracias, segundo Ivo (2004, p. 57):

A política social é uma dimensão necessária da democracia nas sociedades modernas e está estreitamente ligada aos valores da eqüidade que fundam a legitimidade política e a concepção que as sociedades e os governos têm do seu projeto político e de seu destino. [...] as políticas sociais integram um sistema de ação complexo resultante de múltiplas causalidades e diferentes atores e campos de ação social e pública [...] que possibilitem a superação das desigualdades e o exercício pleno da cidadania [...]. Atuando no âmbito redistribuitvo, elas envolvem necessariamente relações de poder e são, portanto, conflitivas e qualificadoras da democracia e do projeto de inclusão social das sociedades.

A vulnerabilidade gerada pela precarização do trabalho tem mostrado, em maior ou menor medida, que a participação na sociabilidade urbana dos sujeitos que vivenciam os processos de exclusão ainda é condicionada pelo tipo de trabalho ou ocupação que exercem. Isso implica que

... não se pode compreender os dilemas da política social fora da dimensão do trabalho, entendido como a forma concreta de reprodução e insercão social e como valor histórico e culturalmente instituído, que confere identidade social e matriz de sociabilidade no marco de uma constrição coletiva (Ivo, 2004, p. 57)

Ao ignorar essa dimensão concreta e valorativa, as políticas sociais tornam-se impositivas. Assim, nos processos de vulnerabilização, contam muito mais as regras que se impõem aos excluídos, para que participem - ou ao menos se sintam participantes - dos jogos de sociabilidade.

Entretanto, esses novos condicionamentos implicam, também, que o campo de ações dos sujeitos contemporâneos é plural, o que inclui mesmo a sociabilidade configurada em condições de privação social, como na pobreza ou nos processos de exclusão. Essa condição impõe uma constante necessidade de refletir e redefinir ações sociais na esfera acadêmica ou governamental, atentando aos critérios de comunidade e seus padrões de sociabilidade, configurados nos processos de exclusão territorialmente definidos nas cidades. 
Dessa forma, as análises que buscam estabelecer uma correspondência efetiva entre os planos de sociabilidade vivenciados pelos sujeitos em processos de exclusão e as políticas públicas que a eles se dirigem mostram que esse é ainda um processo aberto.

(Recebido para publicação em maio de 2008) (Aceito em julho de 2008)

\section{REFERÊNCIAS}

ABRAMOVAY, M. (Org.). Juventude, violência e vulnerabilidade social na América Latina: desafios para as políticas públicas. Brasília: Unesco; BID, 2002. 184 p. ANTUNES, Ricardo. Adeus ao trabalho? São Paulo: Cortez, 1994. 155p.

ATKINSON, Roger. Combatendo a exclusão social urbana; o papel da participacão comunitária na regeneracão das cidades européias. Cadernos IPPUR, Rio de Janeiro, IPPUR/UFRJ, v.12, n.1, p.107-128, 1998.

BAUMAN, Zygmunt. Identidade. Rio de Janeiro: Jorge Zahar, 2005. $110 \mathrm{p}$.

BERGER, Brigitte; BERGER, Peter. O que é uma instituiÇão social? In: MARTINS, J.S.; FORACCHI, M.M. (Org.) Sociologia e sociedade: leituras de introdução à sociologia. São Paulo: LTC, 1977. p.193-199.

BERLINCK, M. Marginalidade social e relações de classes em São Paulo. Petrópolis, RJ: Vozes, 1975. 152 p.

CALVINO, ítalo. As cidades invisíveis. São Paulo: Cia. das Letras, 1990. $150 \mathrm{p}$.

CARVALHO, Maria do Carmo B. A reemergência das solidariedades microterritoriais na formatação da política social contemporânea. São Paulo em Perspectiva, São Paulo, v.11, n.4, p.16-21, 1997

CASTEL, Robert. As metamorfoses da questão social: uma crônica do salário. Petrópolis: Vozes, 1999, 611 p.

CATTANI, Antonio D. A vida precária: bases para a nova submissão. In: CATTANI, A.D.; DIAZ, L.M. (Org.). Desigualdades na América Latina: novas abordagens analíticas. Porto Alegre: Ed.UFRGS, 2005. p.51-72.

DRAIBE, Sonia M. Uma nova institucionalidade das políticas sociais? Reflexões a propósito da experiência latino-americana de reforma dos programas sociais. São Paulo em Perspectiva, São Paulo, v.11, n.1, p.3-15, 1997.

DUBET, François. Sociologia da experiência. Lisboa: Instituto Piaget, 1996. $282 \mathrm{p}$.

DUPAS, Gilberto. Economia global e exclusão social; pobreza, desemprego, Estado e o futuro do capitalismo. 2.ed. Rio de Janeiro: Paz e Terra, 1999. 219 p.

EWALD, F. Nacionalizar o social. In: ROSANVALLON, P. La nouvelle question sociale: repenser l'État-providence. Paris: Seuil, 1995

FREITAG, Barbara. A teoria crítica: ontem e hoje. 3.ed. São Paulo: Brasiliense, 1990. 157 p.

GIDDENS, Anthony. As conseqüências da modernidade. 2.ed. São Paulo: Unesp, 1991. 177 p.
HABERMAS, Jürgen. $O$ discurso filosófico $d a$ modernidade. Lisboa: Publicações Dom Quixote, 1990. $350 \mathrm{p}$.

HESPANHA, Pedro. The activation trend in the portuguese social policy. An open process? In: CURSO QUESTÕES ATUAIS DE TEORIA E PESQUISA EM CIÊNCIAS SOCIAIS. São Leopoldo,RS: PPG, Ciências Sociais Unisinos, 8-9 maio 2007. 35p.

HINKELAMMERT, F. Crítica à razão utópica. São Paulo: Paulinas, 1986. 307p.

HONNETH, Axel. Integrity and disrespect; principles of a conception of morality based on the theory of recognition. Political Theory, [S.1.], v. 20, n.2, p. 187-201, 1992.

Luta por reconhecimento: a gramática moral dos conflitos sociais. São Paulo: Editora 34, 2003. 291 p.

IANNI, Octávio. Pensamento social no Brasil. Bauru: EDUSC; ANPOCS, 2004. $366 \mathrm{p}$.

IVO, Anete B. L. A reconversão do social: dilemas da redistribuição no tratamento focalizado. São Paulo em Perspectiva, São Paulo, Fundação Seade, v.18, n.2, p.5767, 2004.

KOWARICK, Lúcio. Capitalismo e marginalidade na América Latina. 2.ed. São Paulo: Paz e Terra, 1975. 187 p.

Sobre a vulnerabilidade socioeconômica e civil; Estados Unidos, França e Brasil. Revista Brasileira de Ciências Sociais, São Paulo, v.18, n.51, p.61-85, 2003.

LEFEBVRE, Henri. A práxis como processo. In: MARTINS, J.S.; FORACCHI, M.M. (Org.) Sociologia e sociedade: leituras de introdução à sociologia. São Paulo: LTC, 1977. p.175-190.

LOPES, José Rogério. Urbanidade e cidadania: as modulacões do urbano e o direito à cidade. Ciências Sociais Unisinos, São Leopoldo,RS, Unisinos, v. 37, n.158, p.6792, 2001a.

Políticas sociais e o enfrentamento do reordenamento institucional e público em regiões de desenvolvimento da sociedade brasileira: relatório final de pesquisa. São Paulo: Fapesp, 2001b.

Movimentos sociais, negociação da realidade e

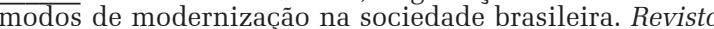
de Educação Pública, Cuiabá, v.16, n.31, p. 3-28, maio/ ago., 2007.

MAIOLINO, Ana L. G.; MANCEBO, Deise. Análise histórica da desigualdade: marginalidade, segregacão e exclusão. Psicologia \& Sociedade, Porto Alegre, v.17, n.2, p.1420, mai/ago., 2005.

MARCUSE, Herbert. Ideologia da sociedade industrial. Rio de Janeiro: Zahar, 1967. 238 p.

MARICATO, Ermínia. As idéias fora do lugar e o lugar fora das idéias: planejamento urbano no Brasil. In: ARANTES, O.; VAINER, C.; MARICATO, E. (Org.). A cidade do pensamento único; desmanchando consensos. Petrópolis: Vozes, 2000. p.121-192.

MARTINS, C. E. Da globalização da economia à questão al no Brasil. Brasília: MPAS/SAS, 1996.

MARTINS, José S. Exclusão social e a nova desigualdade. São Paulo: Paulus, 1997. 140 p.

NASCIMENTO, Elimar P. Hipóteses sobre a nova exclusão social; dos excluídos necessários aos excluídos desnecessários. Cadernos CRH: revista do Centro de Recursos Humanos da UFBA, Salvador, n.21, p.29-47, 1994.

NUN, José. Superpopulación relativa, ejército industrial de reserva y masa marginal. Revista Latinoamericana de Sociologia, Buenos Aires, v.5, n.2, jul., 1969. 
OLIVEIRA, L. Os excluídos existem? Notas sobre a elaboração de um novo conceito. Revista Brasileira de Ciência Sociais, São Paulo, Anpocs, v.12, n.33, p.49-60, 1997.

PASTORINI, Alejandra. A categoria "questão social” em debate. São Paulo: Cortez, 2004. 120 p.

PAUGAM, Serge. O conceito de desqualificação social. In VERAS, M.P.B. (Ed.). Por uma sociologia da exclusão so cial: o debate com Serge Paugam. São Paulo: Educ, 1999 p.63-80.

QUIJANO, Aníbal. Notas sobre o conceito de marginalidade. In: PEREIRA, Luiz (Org.). Populações marginais. São Paulo: Duas Cidades, 1978. 196 p.

RIBEIRO, Luiz Cesar Q. (Org.), O futuro das metrópole desigualdades e governabilidade. Rio de Janeiro: Revan; FASE, 2000. $630 \mathrm{p}$

ROGERS, G.; GORE, C.; FIGUEIREDO, J. (Org.). Socia exclusion: rethoric, reality, responses. Genebra: International Institute for Labor Studies, 1995.

ROSANVALLON, Pierre. La nouvelle question sociale: repenser l'État providence. Paris: Seuil, 1995.

SANTOS, Milton. O espaço do cidadão. São Paulo: Nobel, 1987. $142 \mathrm{p}$. $88 \mathrm{p}$. Espaço e método. 4.ed. São Paulo: Nobel, 1997.

SEN, Amartya. Desenvolvimento como liberdade. São Paulo: Cia das Letras, 2000. 409 p.

SINGER, Paul. Desemprego e exclusão social. São Paulo em Perspectiva, São Paulo, Fundação Seade, v.10, n.1, p.3$12,1996$.

SOUZA, Celina. Estado do campo da pesquisa em políticas públicas no Brasil. Revista Brasileira de Ciências Sociais, São Paulo, Anpocs, v.18, n.51, p.15-20, 2003.

Governos locais e gestão de políticas universais São Paulo em Perspectiva, São Paulo, Fundação Seade v.18, n.2, p.27-41, 2004.

SOUZA, Jessé de. Modernização periférica e naturalização da desigualdade: o caso brasileiro. In: SCALON, Maria C. (Org.). Imagens da desigualdade. Belo Horizonte: Ed. UFMG; Rio de Janeiro: IUPERJ, 2004. p.75-114.
. Uma teoria crítica do conhecimento. Lua Nova, São Paulo, Cedec, n.50, p.133-158, 2000.

SUNG, Jung M. Sujeito e sociedades complexas: para repensar os horizontes utópicos. Petrópolis: Vozes, 2002. $181 \mathrm{p}$.

TOURAINE, Alain. Um novo paradigma para compreender o mundo de hoje. Petrópolis: Vozes, 2006. 258 p.

. Podremos vivir juntos? Iguales y diferentes. 2.ed. México: Fondo de Cultura Economica, 2000. 335 p.

Os novos conflitos sociais; para evitar mal-entendidos. Lua Nova, São Paulo, Cedec, n.17, p.5-18, 1989.

VERAS, Maura P. B. (Ed.). Por uma sociologia da exclusão social: o debate com Serge Paugam. São Paulo: Educ, 1999. $142 \mathrm{p}$.

Exclusão social: um problema brasileiro de 500 anos, In: SAWAIA, B. S. (Org.). As artimanhas da exclusão; análise psicossocial e ética da desigualdade social. Petrópolis, RJ: Vozes, 1999a. p. 27-50.

WANDERLEY, Mariângela B. Refletindo sobre a noção de exclusão. Serviço Social \& Sociedade, São Paulo, Cortez, n.55, p.74-83, 1997.

WANDERLEY, Luiz E. W. A questão social no contexto da globalização: o caso latino-americano e o caribenho. In: BÓGUS, L.; YAZBEK, M.C.; WANDERLEY, M.B. (Org.) Desigualdade e a questão social. São Paulo: Educ, 1997 p.51-161.

WEBER, Max. Ensaios de sociologia. Rio de Janeiro: Zahar, 1982. $530 \mathrm{p}$.

XIBERRAS, M. As teorias da exclusão; para uma construção do imaginário do desvio. 2.ed. Lisboa: Instituto Piaget, 1993. $251 \mathrm{p}$.

ZALUAR, Alba. Exclusão e políticas públicas: dilemas teóricos e alternativas políticas. Revista Brasileira de Ciências Sociais, São Paulo, v.12, n.35, 1997. Disponível em: www.scielo.br/scielo.php?script=sci_arttext \&pid =S 0102-69091997000300003\&lng=pt\& $\bar{n} r m i s o$. Acesso em: 20 jul 2007. Pré-publicação.

ZARTH, P. A. et al. Os caminhos da exclusão social. IjuíRS: Ed.Unijuí, 1998. 


\section{SOCIAL PROCESSES OF EXCLUSION AND PUBLIC POLICIES OF FIGHTING POVERTY}

\section{José Rogério Lopes}

This paper revises several authors' theoretical contributions that approach the processes of "social exclusion" as a group of references configured historically in the dynamics of internationalization of the economy. This review indicates the need to distinguish among the public policies of "combat to exclusion" and those that self-attribute a characteristic of inclusion, to justify the complementarity of both. Categories and analytic elements stand out (such as the current debate between redistribution and recognition, in the field of of rights and of public policies demands) that allow identification of new social conditionings that affect the senses produced by the subjects in vulnerability conditions or privations generated in urban poverty, important to guide a review of the guidelines for the policies at hand.

\section{PROCESSUS SOCIAUX D'EXCLUSIONET POLITIQUES PUBLIQUES DE LUTTE CONTRE LA PAUVRETÉ}

\author{
José Rogério Lopes
}

Ce texte revoit les contributions théoriques des auteurs qui abordent les processus "d'exclusion sociale" comme un ensemble de références configurées historiquement dans la dynamique de l'internationalisation de l'économie. Cette révision montre le besoin de faire la distinction entre les politiques publiques de "combat contre l'exclusion" et celles qui s'auto attribuent un aspect d'inclusion afin de pouvoir justifier la complémentarité entre les deux. Des catégories et des éléments de l'analyse sont mis en évidence (tels que le débat actuel entre la redistribution et la reconnaissance, dans le domaine des revendications des droits et des politiques publiques) qui permettent d'identifier de nouveaux conditionnements sociaux, capables d'affecter les sens, produits par les personnes se trouvant en conditions de vulnérabilité ou de privations causées au sein de la pauvreté urbaine. Ces catégories et ces éléments sont importants pour orienter une révision des directives des politiques en question.

KEYWORDS: exclusion processes, internationalization of MOTS-CLÉS: processus d'exclusion, internationalisation the economy, public policies, vulnerabilities, privations. de l'économie, politiques publiques, vulnérabilités, privations. 